Article

\title{
Carotenoids in Fruits of Different Persimmon Cultivars
}

\section{Chunhua Zhou ${ }^{1}$, Daqiu Zhao ${ }^{1}$, Yanle Sheng ${ }^{1}$, Jun Tao ${ }^{1, *}$ and Yong Yang ${ }^{2}$}

1 College of Horticulture and Plant Protection, Yangzhou University, Yangzhou 225009, China; E-Mails: chzhou@yzu.edu.cn (C.Z.); 405323488@qq.com (D.Z.); ylsheng2007@163.com (Y.S.)

2 College of Horticulture, Northwest A \&F University, Yangling 712100, China; E-Mail: yang.yong521@163.com (Y.Y.)

* Author to whom correspondence should be addressed; E-Mail: taojun@yzu.edu.cn; Tel.: +86 514 87997219; Fax: +8651487347537.

Received: 9 November 2010; in revised form: 21 December 2010 / Accepted: 11 January 2011 / Published: 17 January 2011

\begin{abstract}
Carotenoids in the peel and the flesh of persimmon fruit were identified, and the contents of carotenoids in the fleshes of 46 different persimmon cultivars were analyzed. The results indicated that 31 specific carotenoids were detected in both cultivars of persimmons, among which nine specific carotenoids were characterized. $\beta$-Cryptoxanthin was the most abundant carotenoid among all individual components in both the peel and the flesh, accounting for about $20-30 \%$ of the total carotenoids in both cultivars. The contents of total carotenoids in the fleshes of different persimmon cultivars were between $194.61 \mu \mathrm{g} / 100 \mathrm{~g}$ FW and 1,566.30 $\mu \mathrm{g} / 100 \mathrm{~g} \mathrm{FW}$. Zeaxanthin was also the most abundant in all persimmon fleshes besides $\beta$-Cryptoxanthin, and the total amount of these two components accounted for $37.84-85.11 \%$ of the total carotenoids. The RE values in the fleshes of different cultivars also differed greatly. Besides, the stage of maturation was also important factor which could influence the carotenoid content and RE value in the fleshes.
\end{abstract}

Keywords: carotenoids; provitamin A; HPLC; persimmon

\section{Introduction}

Persimmon (Diospyros kaki L.) is an important horticultural crop which has many cultivated varieties. Based on the statistics of FAO (2009), the annual production of persimmon in China is about 2.68 million tons, accounting for about $70.0 \%$ of the total world production [1]. Persimmon fruit 
contains different nutrients and phytochemicals such as carbohydrates, organic acids, vitamins, tannins, polyphenols, dietary fibers and carotenoids etc., which play important roles in the flavor, color, nutritive and pharmaceutical value of the fruit [2-5].

Carotenoids are biosynthesized by photosynthetic organisms as well as non-photosynthetic bacteria and fungi. The plant carotenoids are dominated by $\mathrm{C}_{40}$ isoprenoids with polyene chains containing as many as 15 conjugated double bonds which can be divided into two groups: hydrocarbons (carotenes) and their oxidation derivatives (xanthophylls). These compounds are not only responsible for the yellow, orange and red colors of foods [6], but are also the precursors of vitamin A [7]. Besides, they play multiple roles in the prevention or protection of diseases seriously impairing the human health by oxidative damage, such as heart diseases, cardiovascular diseases, cancers and age-related macular degeneration $[8,9]$.

The persimmon fruit is very captivating, and the color varies in different cultivars from yellow, and orange to deep red. The researchers found that fruit color mainly resulted from the carotenoids, and $\beta$-cryptoxanthin was the most abundant among all carotenoids in both the peel and the flesh [3,5]. In the previous studies on carotenoids in persimmon fruit, most of them were based on open-column chromatography or the combination of column chromatography and thin layer chromatography [5,10-13]. Subsequently, high performance liquid chromatography (HPLC) equipped with ultraviolet/visible light detector and $\mathrm{C}_{18}$ reverse phase column was also applied to analyze the carotenoids. However, the cultivars covered were few [14,15], and only a few specific components such as $\alpha$-carotene, $\beta$-carotene and $\beta$-cryptoxanthin were analyzed $[5,16,17]$. Therefore, it is very important to obtain the more detailed information about the carotenoids in persimmon fruit, especially the flesh, the edible part of fruit. The objective of this research was to identify the carotenoids in the peel and the flesh of persimmon fruit and compare the differences between the compositions and contents of carotenoids in the fleshes of different persimmon cultivars using HPLC-PDAD with a $\mathrm{C}_{30}$ reverse phase column. Besides, the effect of different stage of maturation on the contents of carotenoids in the flesh of persimmon fruit was also investigated.

\section{Results and Discussion}

\subsection{Evaluations of fruit quality indexes and color}

The fruit size, shape, TSS and titratable acid content varied due to the different cultivars regardless of whether they were non-astringent persimmons or astringent persimmon (Table 1). The difference of the fruit shapes among all the astringent persimmon cultivars was larger than that among the non-astringent persimmon cultivars, and the average weight of individual fruits of the astringent persimmon cultivars was heavier than that of the non-astringent persimmon cultivars. The average TSS content of the astringent persimmon cultivars was lower than that of the non-astringent persimmon, however, the trend of the titratable acid was reversed. The huge differences of quality indexes among different cultivars might result from the different genetic origins.

During the edible period of persimmons, the difference of the peel color between the astringent persimmons and the non-astringent persimmons was similar to the difference that existed between red-fleshed and white-fleshed loquat fruits [18]. $L^{*}$ values and $C^{*}$ values of the astringent cultivars were slightly lower than those of the non-astringent cultivars, which reflected that the deeper color 
might be caused by the higher abundance of carotenoids. Through comparisons, the $a^{*}$ value of the astringent cultivars was higher, while the $b^{*}$ value was slightly lower, and as a result, the $a^{*} / b^{*}$ ratio was higher. The $a^{*} / b^{*}$ ratio was negative for green fruits, zero for yellow fruits, and positive for orange fruits [19]. Higher value of the positive ratio $a^{*} / b^{*}$ indicated that the color was redder, therefore, the peel color of the astringent persimmons was redder than that of the non-astringent cultivars. Alternatively, the color could be well described by hue angle $\left(H^{\circ}\right)$ as follows: $0^{\circ}$ for red-purple, $90^{\circ}$ for yellow, and $180^{\circ}$ for bluish-green and $270^{\circ}$ for blue [20]. Therefore, the average hue angle of the astringent persimmon cultivars and non-astringent persimmon cultivars were $60^{\circ}$ and $80^{\circ}$, respectively, indicating that the colors of these two kinds of persimmons tended to be orange and yellow, respectively.

Table 1. Major quality and color indexes in the fleshes of different persimmon cultivars.

\begin{tabular}{|c|c|c|c|c|c|c|c|c|c|c|c|c|}
\hline Cultivars & $\begin{array}{l}W^{a} \\
(\mathrm{~g})\end{array}$ & $\begin{array}{l}V^{b} \\
(\mathrm{~cm})\end{array}$ & $\begin{array}{l}\mathrm{HD}^{c} \\
(\mathrm{~cm})\end{array}$ & FSI $^{d}$ & $\begin{array}{c}\text { TSS }^{e} \\
\left({ }^{\circ} \text { Brix }\right)\end{array}$ & $\begin{array}{l}\text { TA }^{f} \\
(\%)\end{array}$ & $L^{*}$ & $a^{*}$ & $b^{*}$ & $\mathrm{H}^{o}$ & $C^{*}$ & $a^{* 1} b^{*}$ \\
\hline \multicolumn{13}{|c|}{ Astringent persimmons } \\
\hline Boaidashuishi & 53.29 & 3.34 & 4.94 & 0.68 & 13.75 & 0.22 & 53.16 & 21.07 & 39.78 & 62.09 & 45.02 & 0.53 \\
\hline Changanhuoguan & 70.82 & 4.58 & 4.96 & 0.92 & 14.78 & 0.38 & 45.28 & 20.14 & 28.48 & 54.73 & 34.88 & 0.71 \\
\hline Fujianding & 136.73 & 5.54 & 6.26 & 0.88 & 15.46 & 0.25 & 41.16 & 14.88 & 23.15 & 57.27 & 27.52 & 0.64 \\
\hline Heixins & 94.73 & 5.05 & 5.61 & 0.90 & 11.11 & 0.37 & 50.83 & 17.10 & 35.54 & 64.31 & 39.44 & 0.48 \\
\hline Heshi & 339.35 & 6.63 & 9.38 & 0.71 & 16.25 & 0.19 & 56.04 & 25.68 & 44.60 & 60.07 & 51.46 & 0.58 \\
\hline Hiratan & & 4.18 & 6.29 & 0.66 & 15.64 & 0.19 & & 20.21 & & 58.14 & 38.29 & 0.62 \\
\hline Hiro & 101.73 & 4.82 & 5.92 & 0.81 & 15.20 & 0.18 & 43.67 & 5.17 & 25.14 & 78.38 & 25.67 & 0.21 \\
\hline Jianshi & 122.70 & 6.33 & 5.69 & 1.11 & 16.31 & 0.30 & 48.06 & 15.49 & 32.93 & & 36.39 & 0.47 \\
\hline Jincheng & 66.27 & 3.67 & 5.22 & 0.70 & 16.80 & 0.18 & 47.66 & 24.35 & 34.17 & 54.53 & 41.96 & 0.71 \\
\hline Jinshi & 277.98 & 7.56 & 7.45 & 1.01 & 13.24 & 0.20 & 48.11 & 15.90 & 32.06 & 63.62 & 35.79 & 0.50 \\
\hline Kangding No.1 & 77.08 & 4.28 & 5.08 & 0.84 & 18.57 & 0.20 & 52.02 & 25.04 & 40.37 & 58.19 & 47.51 & 0.62 \\
\hline Lantianshuishi & 148.58 & 5.69 & 6.48 & 0.88 & 14.26 & 0.26 & 53.81 & 9.25 & 37.09 & 76.00 & 38.23 & 0.25 \\
\hline Mantia & 209.03 & 5.92 & 7.72 & 0.77 & 16.57 & 0.17 & 42.96 & 29.32 & 29.58 & 45.25 & 41.65 & 0.99 \\
\hline Mendu & 81.66 & 5.05 & 5.45 & 0.93 & 18.15 & 0.12 & 52.71 & 23.85 & 41.00 & 59.81 & 47.43 & 0.58 \\
\hline Mian & & 4.92 & & 0.92 & & 0.33 & & & & & & 0.45 \\
\hline Mimiguan & 48.28 & 4.41 & 4.33 & 1.02 & 15.48 & 0.38 & 46.52 & 26.14 & 30.47 & 49.37 & 40.15 & 0.86 \\
\hline & & 5.17 & & 0.80 & & 0.24 & & 19.49 & & 58.41 & & 0.62 \\
\hline Ribenhongs & 96.64 & 4.29 & 5.82 & 0.74 & 18.57 & 0.17 & 47.77 & 23.43 & 32.07 & 53.85 & 39.72 & 0.73 \\
\hline Rongxianjingshi & 183.40 & 5.60 & 6.68 & 0.84 & 21.15 & 0.25 & 39.79 & 22.39 & 24.16 & 47.18 & 32.94 & 0.93 \\
\hline Shagu No.1 & 106.00 & 4.72 & 5.97 & 0.79 & 15.01 & 0.23 & 43.54 & 13.36 & 26.61 & 63.34 & 29.78 & 0.50 \\
\hline Tianfushi & 123.34 & 4.96 & 6.22 & 0.80 & 14.40 & 0.14 & 47.13 & 19.29 & 32.65 & 59.42 & 37.92 & 0.59 \\
\hline Tonewase & 215.10 & 5.57 & 7.95 & 0.70 & 17.50 & 0.20 & 38.65 & 21.58 & 22.98 & 46.80 & 31.52 & 0.94 \\
\hline Xiaodishi & 96.13 & 4.09 & 5.84 & 0.70 & 15.12 & 0.22 & 51.03 & 26.79 & 36.85 & 53.98 & 45.56 & 0.73 \\
\hline Xiaoercao & 35.72 & 3.19 & 4.30 & 0.74 & 12.38 & 0.24 & 52.07 & 17.00 & 36.40 & 64.97 & 40.17 & 0.47 \\
\hline Xiaofangshi & 138.00 & 4.83 & 6.49 & 0.74 & 14.53 & 0.33 & 47.53 & 17.01 & 31.80 & 61.86 & 36.06 & 0.53 \\
\hline Xinchangniuxinshi & 97.78 & 6.14 & 5.15 & 1.19 & 13.04 & 0.33 & & 19.73 & 37.49 & 62.24 & 42.36 & 0.53 \\
\hline Xingyangbaheshi & 84.16 & 4.09 & 5.58 & 0.73 & 14.94 & 0.15 & 47.20 & 15.81 & 30.27 & 62.42 & 34.15 & 0.52 \\
\hline Yangshuohuoshi & 63.60 & 3.71 & 5.20 & 0.71 & 14.25 & 0.16 & 47.18 & 13.92 & 34.92 & 68.27 & 37.59 & 0.40 \\
\hline Yichuanling & 63.28 & 4.42 & 4.72 & 0.94 & 15.20 & 0.14 & 50.62 & 23.37 & 40.19 & 59.82 & 46.49 & 0.58 \\
\hline Yueshi & 153.82 & 4.69 & 5.79 & 0.81 & 14.90 & 0.27 & 45.97 & 9.78 & 31.53 & 72.77 & 33.01 & 0.31 \\
\hline
\end{tabular}


Table 1. Cont.

\begin{tabular}{lcccccccccccc}
\hline Zhaotianhong & 159.40 & 4.86 & 7.21 & 0.67 & 15.50 & 0.20 & 41.31 & 21.67 & 21.02 & 44.13 & 30.19 & 1.03 \\
Zhengyangjiandingshi & 99.23 & 4.29 & 6.09 & 0.70 & 11.88 & 0.16 & 55.58 & 22.68 & 45.23 & 63.37 & 50.60 & 0.50 \\
Average & 121.45 & 4.89 & 5.99 & 0.82 & 15.34 & 0.23 & 47.81 & 19.21 & 32.93 & 59.85 & 38.46 & 0.60 \\
Non-astringent persimmons & & & & & & & & & & & \\
Eshi No.1 & 143.65 & 4.90 & 7.06 & 0.69 & 15.38 & 0.20 & 43.74 & -7.25 & 25.12 & 106.10 & 26.15 & -0.29 \\
Hanagosho & 111.90 & 5.16 & 6.39 & 0.81 & 21.58 & 0.09 & 51.76 & 5.80 & 37.50 & 81.21 & 37.95 & 0.15 \\
Jirou & 114.54 & 4.41 & 6.64 & 0.66 & 13.34 & 0.11 & 64.00 & 3.49 & 50.55 & 86.05 & 50.67 & 0.07 \\
Luotiantianshi & 57.02 & 4.01 & 4.78 & 0.84 & 15.65 & 0.14 & 51.74 & 14.15 & 39.75 & 70.41 & 42.19 & 0.36 \\
Matsumotowase & 59.20 & 4.21 & 5.21 & 0.81 & 17.19 & 0.15 & 62.08 & -11.14 & 47.66 & 103.16 & 48.94 & -0.23 \\
Nishimurawase & 115.58 & 4.57 & 6.75 & 0.68 & 16.39 & 0.21 & 57.32 & 9.58 & 44.24 & 77.78 & 45.27 & 0.22 \\
Okugosho & 100.68 & 4.56 & 6.16 & 0.74 & 18.16 & 0.27 & 56.22 & 23.49 & 44.59 & 62.22 & 50.40 & 0.53 \\
Sifangtianshi & 24.44 & 2.82 & 3.51 & 0.80 & 19.77 & 0.14 & 49.29 & 10.80 & 34.10 & 72.43 & 35.77 & 0.32 \\
Suruga & 93.38 & 4.75 & 6.08 & 0.78 & 13.19 & 0.09 & 61.14 & 1.21 & 49.23 & 88.59 & 49.24 & 0.02 \\
Uenishiwase & 128.90 & 5.31 & 6.73 & 0.79 & 16.97 & 0.13 & 55.15 & 8.80 & 39.65 & 77.49 & 40.61 & 0.22 \\
Xiangxitianshi & 110.40 & 4.56 & 6.49 & 0.70 & 15.33 & 0.14 & 59.96 & 11.14 & 45.52 & 76.25 & 46.86 & 0.24 \\
Xiaoguotianshi & 28.29 & 3.32 & 3.83 & 0.87 & 24.76 & 0.12 & 55.30 & 8.53 & 44.68 & 79.19 & 45.49 & 0.19 \\
Youhou & 152.76 & 5.05 & 7.26 & 0.70 & 14.11 & 0.11 & 62.16 & 1.74 & 49.65 & 87.99 & 49.68 & 0.04 \\
Zenjimaru & 135.65 & 5.29 & 6.43 & 0.82 & 14.10 & 0.21 & 47.86 & 22.53 & 28.74 & 51.91 & 36.52 & 0.78 \\
Average & 98.31 & 4.49 & 5.95 & 0.76 & 16.85 & 0.15 & 55.55 & 7.35 & 41.50 & 80.06 & 43.27 & 0.19 \\
\hline
\end{tabular}

${ }^{a} \mathrm{~W}$ : Weight; ${ }^{b}$ VD: Vertical diameter; ${ }^{c} \mathrm{HD}$ : Horizontal diameter; ${ }^{d}$ FSI: Fruit shape index, The ratio of VD/HD; ${ }^{e}$ TSS: Total soluble solid; ${ }^{f} \mathrm{TA}$ : Titrable acid.

\subsection{HPLC chromatogram of carotenoids in persimmon fruit}

Thirty one specific carotenoids were detected in two persimmon cultivars, among which nine compounds were identified, including neoxanthin, violaxanthin, 9-cis-violaxanthin, lutein, zeaxanthin, $\beta$-cryptoxanthin, $\alpha$-carotene, $\beta$-carotene and lycopene. On the other hand luteoxanthin, $\zeta$-carotene and colorless carotenoids such as phytofluene, phytoene were not detected (Table 2). $\beta$-Cryptoxanthin was the most abundant carotenoids among all components in the peel and the flesh of 'Xiaofanshi' (astringent persimmon) and 'Youhou' (non-astringent persimmon), accounting for about 20-30\% of the total carotenoids in both cultivars, which was consistent to the previous results $[3,5]$. In the peels of two cultivars, the contents of lutein were higher than those of zeaxanthin, while the contents of $\beta$-carotene were lower than those of lutein and zeaxanthin. The total contents of $\beta$-cryptoxanthin, lutein, zeaxanthin and $\beta$-carotene in 'Xiaofangshi' and 'Youhou' accounted for $49.09 \%$ and $51.48 \%$ of the total carotenoids, respectively. In the fleshes, the contents of zeaxanthin in both two cultivars were higher than those of $\beta$-carotene, while the contents of lutein were lower than those of $\beta$-carotene and zeaxanthin. The total contents of $\beta$-cryptoxanthin, zeaxanthin, $\beta$-carotene and lutein in 'Xiaofangshi' and 'Youhou' accounted for $59.47 \%$ and $49.67 \%$ of the total carotenoids, respectively. Among the nine specific carotenoids identified, 9-cis-violaxanthin was only detected in the peels of two cultivars, and was not detected in the flesh of both cultivars. The abundances of the carotenoid in peak 8 in two tissues of 'Youhou' were both the second, while those in the flesh and the peel of 'Xiaofangshi' were the second and third (Table 2), respectively. It was not identified in this study, but is worthy of further analysis and investigation. It could be seen in the HPLC chromatograms that the components of carotenoids in the peels and fleshes of both cultivars were similar (Figure 1). Although zeaxanthin 
cannot be converted into vitamin A in the human body, its protective effects on the neural cell of retina is well known [21]. There are few fruits that accumulate zeaxanthin, wolfberry fruit being a rich source for this substance [22].

Table 2. Separation and identification of carotenoid components in different tissues of the persimmon fruits cv. 'Xiaofangshi' and 'Youhou' by high performance liquid chromatography with photodiode array detection.

\begin{tabular}{|c|c|c|c|c|c|c|c|}
\hline \multirow{3}{*}{$\begin{array}{c}\text { Peak } \\
\text { no. }\end{array}$} & \multirow{3}{*}{ Carotenoids } & \multirow{3}{*}{$\begin{array}{c}\mathbf{R t}^{b} \\
(\mathrm{~min})\end{array}$} & \multirow{3}{*}{$\lambda_{\max }^{c}(\mathbf{n m})$} & \multicolumn{4}{|c|}{ Abundance $^{d}(\%)$} \\
\hline & & & & \multicolumn{2}{|c|}{ Xiaofangshi } & \multicolumn{2}{|c|}{ Youhou } \\
\hline & & & & Peel & Flesh & Peel & Flesh \\
\hline 1 & Neoxanthin & 10.83 & $416,440,469$ & 2.69 & 2.64 & 3.04 & 4.79 \\
\hline 2 & Violaxanthin & 11.26 & $(415), 439,468$ & 5.73 & 3.87 & 7.14 & 4.18 \\
\hline 3 & Unidentified $^{a}$ & 11.85 & $377,423,448$ & $j^{e}$ & 0.65 & / & / \\
\hline 4 & Unidentified & 12.13 & $412,437,463$ & 2.57 & I & 2.84 & 0.51 \\
\hline 5 & Unidentified & 12.40 & $423,451,470$ & 3.51 & 1.62 & 2.23 & 1.46 \\
\hline 6 & Unidentified & 12.71 & $401,425,451$ & / & / & / & 0.47 \\
\hline 7 & Unidentified & 13.12 & $429,445,469$ & l & I & 0.45 & / \\
\hline 8 & Unidentified & 14.05 & $417,446,474$ & 13.11 & 15.07 & 10.98 & 23.72 \\
\hline 9 & 9-Cis-violaxanthin & 14.35 & $412,435,464$ & 4.10 & / & 5.35 & I \\
\hline 10 & Unidentified & 14.83 & $414,442,470$ & 0.64 & / & I & l \\
\hline 11 & Lutein & 16.22 & $(420), 445,473$ & 13.53 & 3.64 & 9.91 & 2.64 \\
\hline 12 & Unidentified & 17.09 & $429,457,485$ & 1.86 & 1.03 & 1.65 & 0.46 \\
\hline 13 & Zeaxanthin & 18.51 & $(427), 450,478$ & 9.40 & 14.70 & 8.59 & 12.79 \\
\hline 14 & Unidentified & 19.02 & $(425), 441,475$ & / & / & 0.49 & I \\
\hline 15 & Unidentified & 19.86 & $(425), 441,470$ & 3.35 & 4.76 & 3.55 & 6.66 \\
\hline 16 & Unidentified & 20.92 & $(427), 451,474$ & 2.11 & 3.19 & 2.87 & 4.12 \\
\hline 17 & Unidentified & 21.27 & $419,443,477$ & 2.93 & 1.06 & 1.10 & l \\
\hline 18 & Unidentified & 21.94 & $422,446,481$ & / & / & 0.72 & l \\
\hline 19 & Unidentified & 22.40 & $(427), 454,481$ & l & / & 0.14 & l \\
\hline 20 & Unidentified & 22.87 & $419,443,468$ & / & / & 0.25 & I \\
\hline 21 & $\beta$-Cryptoxanthin & 23.40 & $(426), 451,479$ & 19.34 & 29.58 & 28.55 & 29.44 \\
\hline 22 & Unidentified & 24.35 & $429,452,479$ & l & / & 0.34 & / \\
\hline 23 & Unidentified & 25.09 & $419,446,476$ & 0.52 & 0.65 & 0.87 & / \\
\hline 24 & Unidentified & 25.63 & $(425), 451,475$ & 0.81 & 1.07 & 0.83 & 0.74 \\
\hline 25 & $\alpha$-Carotene & 26.04 & $(424), 446,474$ & 6.59 & 2.86 & 2.33 & 0.70 \\
\hline 26 & $\beta$-Carotene & 27.90 & $(427), 452,479$ & 6.82 & 11.55 & 4.43 & 4.62 \\
\hline 27 & Unidentified & 29.06 & $(425), 449,474$ & 0.40 & 0.64 & 0.30 & l \\
\hline 28 & Unidentified & 32.44 & $425,458,485$ & / & / & 0.14 & 0.69 \\
\hline 29 & Uunidentified & 35.60 & $413,436,479$ & I & l & 0.14 & I \\
\hline 30 & Unidentified & 36.11 & $421,451,475$ & / & l & 0.09 & 0.54 \\
\hline 31 & Lycopene & 47.44 & $446,473,503$ & 1 & 1.46 & 0.59 & 1.48 \\
\hline
\end{tabular}

${ }^{a}$ Unidentified compounds having carotenoid spectra; ${ }^{b} \mathrm{Rt}=$ retention time; ${ }^{c}$ Obtained with photodiode array detection in mobile solvents; ${ }^{d}$ Expressed as percentage of total carotenoids; ${ }^{e}$ Under the detection limit. 
The results of this study indicated that a great amount of zeaxanthin could also be supplied by the persimmon fruit. Lycopene is the main pigment in tomato [23], watermelon [24], passionflower [25], and the red mutants such as orange, grapefruit and pomelo [26]. Lycopene was detected in the fleshes of both persimmon cultivars and in the peel of "Youhou", however, it was not the main carotenoid in the persimmon fruit.

Figure 1. HPLC chromatograms of the extraction of the saponified carotenoids in the peel and the flesh of persimmon cv. 'Xiaofangshi' and 'Youhou', monitored at $450 \mathrm{~nm}$. The peaks were numbered according to the elution sequence, see Table 2 for detail.
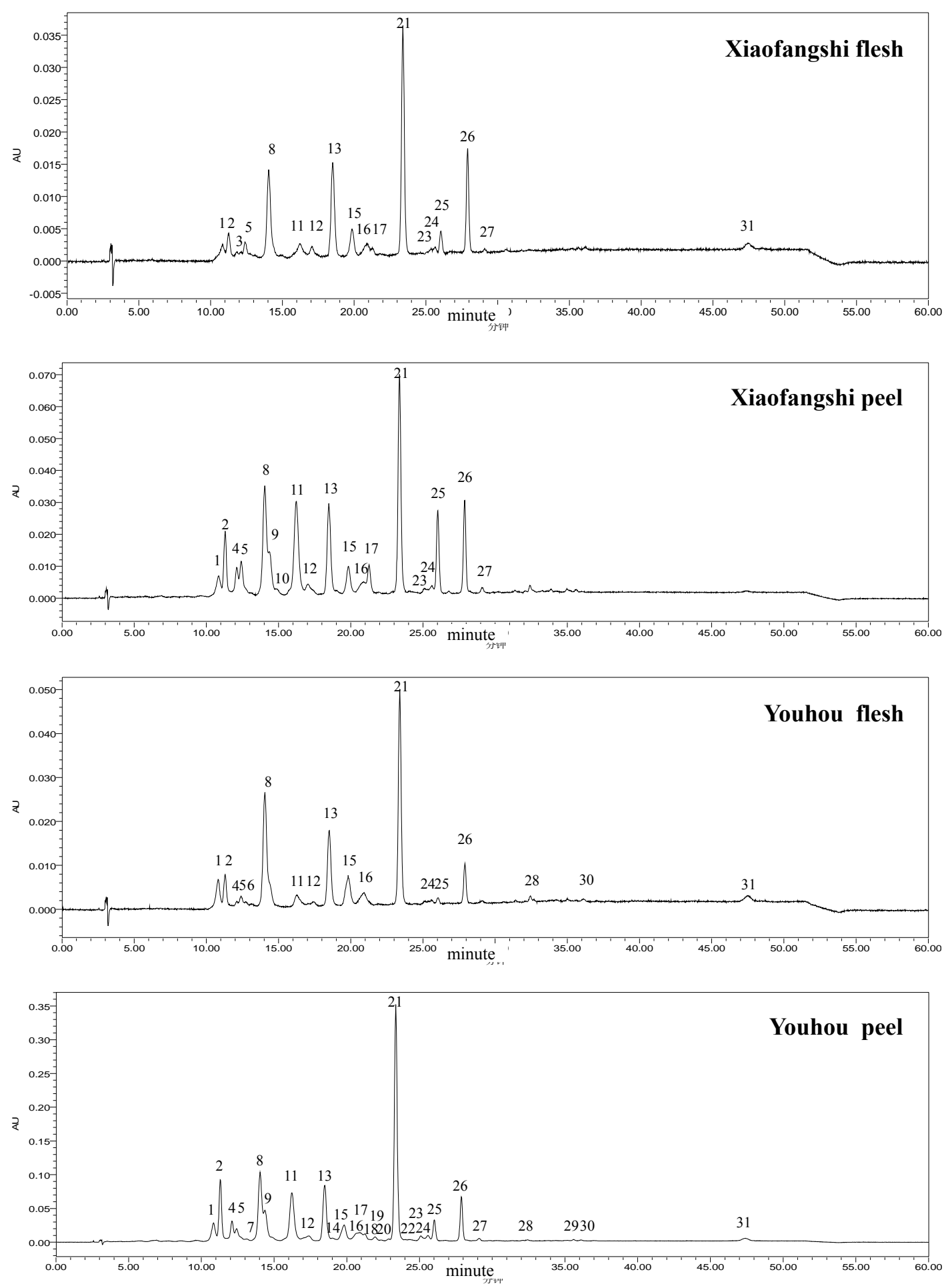


\subsection{Contents of carotenoids in the flesh of different persimmon cultivars}

The flesh is the edible part of the persimmon fruit, therefore, the contents of carotenoids in the flesh of the persimmon fruits of different cultivars were determined, and their RE values were also evaluated. The contents of the total carotenoids and eight specific carotenoids in the fleshes of different persimmon cultivars were significantly different, and the total content of carotenoids were between $194.61 \pm 15.94 \mu \mathrm{g} / 100 \mathrm{~g} \mathrm{FW}$ and 1,566.30 $\pm 116.33 \mu \mathrm{g} / 100 \mathrm{~g} \mathrm{FW}$ (Table 3). Among eight specific carotenoids determined, $\beta$-cryptoxanthin and zeaxanthin were two specific carotenoids whose contents were the highest in all persimmon fleshes. These two components mentioned above accounted for $37.84-85.11 \%$ of the total carotenoids content. The content of $\beta$-cryptoxanthin in the flesh was between $60.91 \pm 0.28 \mu \mathrm{g} / 100 \mathrm{~g} \mathrm{FW}$ and $940.61 \pm 77.50 \mu \mathrm{g} / 100 \mathrm{~g} \mathrm{FW}$, accounting for $21.33-63.92 \%$ of the total content of carotenoids. It was found that the average content of $\beta$-cryptoxanthin $(381.01 \mu \mathrm{g} / 100 \mathrm{~g} \mathrm{FW})$ and its proportion in total carotenoids $(47.40 \%)$ of the astringent persimmon were higher than the average content of $\beta$-cryptoxanthin $(167.43 \mu \mathrm{g} / 100 \mathrm{~g} \mathrm{FW})$ and its proportion in total carotenoids (37.58\%) of the non-astringent persimmon by comparing the differences between the astringent persimmon and the non-astringent persimmon. The content of zeaxanthin in the flesh was between $5.57 \pm 2.19 \mu \mathrm{g} / 100 \mathrm{~g} \mathrm{FW}$ and $501.86 \pm 38.25 \mu \mathrm{g} / 100 \mathrm{~g} \mathrm{FW}$, accounting for $10.53-32.14 \%$ of the total carotenoids content. It was found that the average content of zeaxanthin $(162.15 \mu \mathrm{g} / 100 \mathrm{~g} \mathrm{FW})$ and its proportion in total carotenoids (19.04\%) of the astringent persimmon were higher than the average content of zeaxanthin $(70.16 \mu \mathrm{g} / 100 \mathrm{~g} \mathrm{FW})$ and its proportion in total carotenoids $(17.12 \%)$ of the non-astringent persimmon by comparing the differences between the astringent persimmon and the non-astringent persimmon. In some cultivars, the contents of lutein, $\alpha$-carotene and lycopene were under the detection limits. The difference of lycopene between different cultivars was larger than that of neoxanthin, violaxanthin, lutein and $\alpha$-carotene. The contents of lycopene in the astringent cultivars 'Mantanhong' and 'Tianfushi', which were 112.67 $\pm 4.82 \mu \mathrm{g} / 100 \mathrm{~g}$ FW and 96.59 $\pm 2.34 \mu \mathrm{g} / 100 \mathrm{~g}$ FW, respectively, were relatively higher.

Table 3. The contents of carotenoids in the fleshes of different persimmon cutivars ( $\mu \mathrm{g} / 100 \mathrm{~g} \mathrm{FW})$.

\begin{tabular}{|c|c|c|c|c|c|c|c|c|c|c|}
\hline Cultivars & T-car ${ }^{a}$ & $\mathrm{Neo}^{b}$ & Viola $^{c}$ & Lut $^{d}$ & $\mathrm{Zea}^{e}$ & $\beta_{-C r y p t o} f$ & $\alpha-\mathrm{Car}^{g}$ & $\beta$-Car ${ }^{h}$ & $\operatorname{Lyc}^{i}$ & $\mathbf{R E}^{j}$ \\
\hline \multicolumn{11}{|c|}{ Astringent persimmons } \\
\hline Boaidashuishi & 1213.78 & 65.47 & 69.39 & 34.49 & 240.25 & 358.22 & 2.89 & 46.36 & $/^{k}$ & 37.82 \\
\hline Changanhuoguan & 519.37 & 22.16 & 13.82 & 21.89 & 108.46 & 222.56 & 4.31 & 16.51 & I & 21.66 \\
\hline Fujianding & 602.23 & 21.88 & 22.25 & 7.58 & 71.84 & 334.27 & 3.02 & 36.54 & / & 34.20 \\
\hline Heixinshi & 1292.42 & 48.28 & 47.43 & 11.09 & 166.35 & 678.38 & 3.32 & 48.54 & l & 64.90 \\
\hline Heshi & 927.51 & 29.96 & 64.47 & / & 128.77 & 322.83 & 4.63 & 46.99 & 2.56 & 35.12 \\
\hline Hiratanenashi & 373.18 & 18.37 & 16.68 & 14.25 & 63.80 & 169.86 & 2.39 & 12.86 & 3.99 & 16.50 \\
\hline Hiro & 978.44 & 49.68 & 43.81 & 4.28 & 169.15 & 491.94 & 3.35 & 54.47 & l & 50.35 \\
\hline Jianshi & 1085.88 & 22.36 & 21.63 & 30.59 & 208.46 & 555.19 & 5.88 & 39.45 & 8.95 & 53.33 \\
\hline Jinchengxiaoshi & 458.74 & 13.39 & 12.89 & 1 & 57.96 & 271.11 & 3.33 & 25.33 & 6.15 & 27.09 \\
\hline Jinshi & 352.91 & 5.68 & 4.52 & 2.74 & 86.42 & 192.78 & 2.25 & 25.14 & I & 20.44 \\
\hline Kangding No.1 & 931.33 & 11.98 & 20.08 & 9.75 & 157.55 & 486.79 & 6.25 & 83.92 & / & 55.07 \\
\hline Lantianshuishi & 372.24 & 15.56 & 15.97 & 2.62 & 55.61 & 210.34 & / & 14.38 & l & 19.93 \\
\hline Mantianhong & 1561.72 & 35.95 & 36.37 & 53.93 & 501.86 & 659.18 & 11.65 & 115.43 & 112.67 & 75.14 \\
\hline Mendunshi & 450.52 & 13.12 & 12.24 & 8.25 & 75.43 & 261.88 & 4.64 & 19.52 & I & 25.46 \\
\hline
\end{tabular}


Table 3. Cont.

\begin{tabular}{|c|c|c|c|c|c|c|c|c|c|c|}
\hline Miandanshi & 680.40 & 29.15 & 22.20 & 13.11 & 186.28 & 237.65 & 6.70 & 37.84 & I & 26.67 \\
\hline Mimiguan & 462.05 & 15.66 & 11.60 & 17.19 & 93.08 & 183.72 & 3.53 & 18.68 & 26.43 & 18.72 \\
\hline Naiyoushi & 338.90 & 16.82 & 9.06 & 5.66 & 68.55 & 158.35 & 6.78 & 34.68 & 7.10 & 19.54 \\
\hline Ribenhongshi & 297.45 & 16.79 & 7.58 & 8.04 & 70.80 & 104.42 & I & 18.75 & 13.02 & 11.83 \\
\hline Rongxianjingshi & 1566.30 & 26.73 & 18.32 & 19.91 & 433.91 & 793.35 & 7.62 & 69.14 & 25.33 & 78.27 \\
\hline Shagu No.1 & 958.74 & 20.73 & 24.74 & 29.96 & 203.54 & 447.25 & 5.63 & 36.61 & 29.90 & 43.84 \\
\hline Tianfushi & 777.28 & 36.63 & 19.79 & 12.94 & 136.40 & 268.41 & 5.20 & 64.04 & 96.59 & 33.47 \\
\hline Tonewase & 580.73 & 40.63 & 48.37 & 5.83 & 65.68 & 191.22 & 2.22 & 22.06 & 29.47 & 19.80 \\
\hline Xiaodishi & 383.52 & 8.75 & 15.67 & 2.85 & 53.02 & 210.32 & / & 19.81 & l & 20.83 \\
\hline Xiaoercao & 1562.73 & 24.70 & 54.39 & 55.10 & 364.65 & 757.87 & 7.67 & 65.00 & 11.30 & 74.63 \\
\hline Xiaofangshi & 335.63 & 16.73 & 14.31 & 11.13 & 53.64 & 123.96 & 9.53 & 39.44 & 5.06 & 17.70 \\
\hline Xinchangniuxinshi & 1471.43 & 23.95 & 15.31 & 33.32 & 311.70 & 940.61 & 8.54 & 68.83 & 15.99 & 90.57 \\
\hline Xingyangbaheshi & 1066.04 & 15.86 & 18.16 & 7.76 & 264.39 & 520.71 & 5.94 & 67.31 & 12.66 & 55.11 \\
\hline Yangshuohuoshi & 930.45 & 35.00 & 27.16 & 19.70 & 187.15 & 521.05 & 3.92 & 27.98 & / & 48.41 \\
\hline Yichuanling & 1441.48 & 75.11 & 94.34 & 32.82 & 235.84 & 443.51 & 4.09 & 61.46 & / & 47.54 \\
\hline Yueshi & 492.57 & 22.46 & 16.77 & / & 86.95 & 281.20 & 1 & 16.09 & 4.05 & 26.12 \\
\hline Zhaotianhong & 1274.28 & 35.59 & 48.80 & 27.35 & 134.23 & 599.18 & 9.50 & 91.07 & 41.9 & 65.90 \\
\hline Zhengyangjiandingshi & 771.27 & 14.14 & 15.21 & 3.69 & 146.99 & 418.12 & 2.55 & 28.30 & / & 39.77 \\
\hline Average & 821.72 & 26.54 & 27.60 & 15.87 & 162.15 & 388.01 & 4.60 & 42.89 & 14.62 & 39.87 \\
\hline \multicolumn{11}{|c|}{ Non-astringent persimmons } \\
\hline Eshi No.1 & 285.51 & 18.77 & 15.69 & 25.28 & 47.14 & 60.91 & 5.45 & 25.88 & / & 9.84 \\
\hline Hanagosho & 325.14 & 11.29 & 10.01 & 16.04 & 61.99 & 118.96 & 5.96 & 32.90 & l & 15.89 \\
\hline Jirou & 624.42 & 32.07 & 19.21 & 19.90 & 49.27 & 208.05 & 5.14 & 38.47 & 33.53 & 24.18 \\
\hline Luotiantianshi & 439.07 & 30.55 & 15.70 & 25.79 & 85.29 & 182.49 & 5.41 & 19.13 & l & 18.85 \\
\hline Matsumotowase & 519.44 & 24.30 & 12.75 & 19.62 & 110.79 & 189.41 & 9.05 & 49.76 & 26.86 & 24.83 \\
\hline Nishimurawase & 391.81 & 14.32 & 10.07 & 20.66 & 75.50 & 203.19 & 5.60 & 41.39 & 6.86 & 24.76 \\
\hline Okugosho & 350.70 & 16.65 & 8.90 & 20.51 & 67.67 & 141.97 & 5.17 & 20.45 & 17.49 & 15.67 \\
\hline Sifangtianshi & 567.59 & 20.10 & 16.81 & 9.36 & 74.65 & 274.54 & 2.50 & 22.84 & 36.56 & 26.89 \\
\hline Suruga & 284.65 & 11.90 & 9.77 & 11.57 & 78.01 & 98.11 & 2.82 & 15.16 & 2.91 & 10.94 \\
\hline Uenishiwase & 194.61 & 10.31 & 4.60 & 13.44 & 52.92 & 71.23 & 2.97 & 14.63 & 1 & 8.62 \\
\hline Xiangxitianshi & 339.19 & 29.02 & 11.44 & 18.50 & 35.57 & 144.38 & 7.89 & 24.54 & 7.20 & 16.78 \\
\hline Xiaoguotianshi & 728.84 & 29.59 & 19.93 & 27.55 & 91.27 & 304.38 & 14.19 & 53.13 & / & 35.40 \\
\hline Youhou & 500.13 & 43.31 & 24.84 & 13.760 & 66.67 & 175.59 & 4.24 & 24.99 & 8.37 & 19.15 \\
\hline Zenjimaru & 664.98 & 31.99 & 38.92 & 19.73 & 85.50 & 170.82 & 9.15 & 46.85 & 56.60 & 22.81 \\
\hline Average & 444.01 & 23.16 & 15.62 & 18.69 & 70.16 & 167.43 & 6.11 & 30.72 & 14.03 & 19.58 \\
\hline
\end{tabular}

${ }^{a}$ Total carotenoids; ${ }^{b}$ Neoxanthin; ${ }^{c}$ Violaxanthin; ${ }^{d}$ Lutein; ${ }^{e}$ Zeaxanthin; ${ }^{f} \beta$-Cryptoxanthin; ${ }^{g}$ $\alpha$-Carotene; ${ }^{h} \beta$-Carotene; ${ }^{i}$ Lycopene; ${ }^{j}$ Retinol equivalent; ${ }^{k}$ Under the detection limit.

$\beta$-Cryptoxanthin, $\alpha$-carotene and $\beta$-carotene can be converted into vitamin $A$ in animals and humans. Vitamin A value in fruit can be expressed by $\mu \mathrm{g}$ retinol equivalent ( $\mu \mathrm{g} \mathrm{RE}$ ), and $1 \mu \mathrm{g}$ RE equals to $6 \mu \mathrm{g}$ $\beta$-carotene or $12 \mu \mathrm{g}$ other carotenoids of vitamin A resource, such as $\beta$-cryptoxanthin or $\alpha$-carotene [7]. In all the cultivars tested, the RE value was the highest in 'Xinchangniuxinshi' (90.57 $\mu \mathrm{g} / 100 \mathrm{~g} \mathrm{FW})$; while it was the lowest in 'Uenishiwase' $(8.62 \mu \mathrm{g} / 100 \mathrm{~g} \mathrm{FW})$. The average RE values of the astringent persimmons and the non-astringent persimmons were $39.87 \mu \mathrm{g} / 100 \mathrm{~g} \mathrm{FW}$ and $19.58 \mu \mathrm{g} / 100 \mathrm{~g} \mathrm{FW}$, respectively. 


\subsection{The contents of carotenoids in persimmon fleshes in different stages of maturation}

The contents of carotenoids in the flesh of 'Yueshi' fruit rapidly increased from the green mature period to the soft mature period, and except for lutein and lycopene, the trends of other specific carotenoids were similar to that of the total carotenoids. The content of lutein decreased during fruit maturation, and could not be detected in the soft mature period, while lycopene only existed in a small amount in the persimmon in soft mature period, while $\alpha$-carotene was not detected in the three different stages of maturation. In the green mature period, the content of total carotenoids was only $83.26 \pm 0.50 \mu \mathrm{g} / 100 \mathrm{~g} \mathrm{FW}$. With the maturation of the fruit, the contents of the total carotenoids in the half mature period and soft mature period were $284.39 \pm 10.96 \mu \mathrm{g} / 100 \mathrm{~g} \mathrm{FW}$ and $492.57 \pm 25.03 \mu \mathrm{g} / 100 \mathrm{~g} \mathrm{FW}$, respectively (Table 5), which were 3.42 and 5.92 times of that in green mature period. The total amounts of $\beta$-cryptoxanthin and zeaxanthin in the three mature periods mentioned above accounted for $36.91 \%, 51.34 \%$ and $74.74 \%$ of the total carotenoids, respectively. It meant that $\beta$-carotene, $\beta$-cryptoxanthin and zeaxanthin were mainly produced in the cyclic branch of lycopene [27], and with the maturation of the fruit, the increase of the gene expression level of $\beta$-carotene hydroxylase $(\mathrm{HY} b)$ led to more conversion of $\beta$-carotene to $\beta$-cryptoxanthin and zeaxanthin [28].

Table 4. The contents of carotenoids in the fleshes of persimmon fruit cv. 'Yueshi' in different stages of maturation ( $\mu \mathrm{g} / 100 \mathrm{~g} \mathrm{FW})$.

\begin{tabular}{ccccccccccc}
\hline Mature stage & T-car $^{\boldsymbol{a}}$ & Neo $^{\boldsymbol{b}}$ & Viola $^{c}$ & Lut $^{\boldsymbol{d}}$ & Zea $^{\boldsymbol{e}}$ & $\boldsymbol{\beta}$-Crypto & $\boldsymbol{\alpha}$-Car & $\boldsymbol{\beta}^{\boldsymbol{\beta}}$-Car & Lyc $^{\boldsymbol{i}}$ & $\mathbf{R E}^{\boldsymbol{j}}$ \\
\hline Green mature & 82.36 & 9.86 & 5.93 & 7.98 & 14.24 & 16.16 & 5.24 & $/$ & 2.22 & 2.22 \\
Half ripening & 284.39 & 17.07 & 13.01 & 5.57 & 40.60 & 105.41 & 10.97 & $/$ & 10.61 & 10.61 \\
Soften ripening & 492.57 & 22.46 & 16.77 & $/^{k}$ & 86.95 & 281.20 & 16.09 & 4.05 & 26.12 & 26.12 \\
\hline
\end{tabular}

\section{Experimental}

\subsection{Plant materials and sampling}

In this study, the fruits of 46 persimmon (Diospyros kaki L.) cultivars were used, including 32 astringent and 14 non-astringent ones (Table 1). During the edible period of the persimmons, the fruits of different persimmon cultivars were collected from the National Persimmon Germplasm Nursery in Northwest A\&F University (Yangling, Shanxi, China), Zhenjiang Agricultural Science Institute (Jurong, Jiangsu, China) and Persimmon Germplasm Experimental Station of Huazhong Agricultural University (Wuhan, Hubei, China) and then transferred to the lab. Ten intact fruits in each cultivar were selected to determine the main quality indexes, including the fruit size, shape, color, TSS (Total Soluble Solid) content and titratable acid content, and the results were listed in Table 1. After that, the pedicle was removed, and the persimmon fruit was divided into edible part (flesh) and inedible part (peel), and then they were cut into small pieces and frozen in liquid nitrogen, and then stored at $-20{ }^{\circ} \mathrm{C}$ for analysis. 


\subsection{Fruit quality analysis}

The fruit weight was determined by balance. The vertical and horizontal diameter of the fruit was measured by a vernier caliper. The fruit shape index is the ratio of the vertical and horizontal diameters. TSS was determined by a portable refractometer (Chengdu Optical Instrument Factory, China), and the measurements were performed on the opposite sides of the equatorial plane on each fruit. All the indexes mentioned above were the mean value of 10 fruits. Titratable acid was determined according to the titration method as follows: flesh from 10 fruits $(1 \mathrm{~g})$ was ground with distilled water $(5 \mathrm{~mL})$. After filtration and centrifugation for $10 \mathrm{~min}$ at $10,000 \mathrm{~g}$, the supernatant was brought to $10 \mathrm{~mL}$ with distilled water. The water was heated for $5 \mathrm{~min}$ at $100{ }^{\circ} \mathrm{C}$ to eliminate $\mathrm{CO}_{2}$, and subsequently titrated with fresh $10 \mathrm{mM} \mathrm{NaOH}$ to $\mathrm{pH}$ 8.2. Each sample was repeated for three times.

\subsection{Determination of color}

The color of the opposite sides of the equatorial plane on each fruit were determined by a TC-P2A automatic reflectance spectrophotometer (Beijing Xinaoyike Photoelectric Technology Co. Ltd., China) using three color parameters including $L^{*}, a^{*}$ and $b^{*}$ values. Hue angle $\left(H^{\circ}=\operatorname{arctangent}\left(b^{*} / a^{*}\right)\right)$ and chroma $\left(C^{*}=\left(a^{*^{2}}+b^{*^{2}}\right)^{1 / 2}\right)$ were calculated by the method reported before [29]. Ten fruits were continuously determined to calculate the mean value.

\subsection{Extraction and analysis of carotenoids}

Extraction of carotenoids was performed according to the method reported by Zhou et al. with some modifications [18]. A suitable amount of the peel or the flesh was collected, liquid nitrogen was added, and then they were fully ground. Subsequently, sample $(200 \mathrm{mg})$ was weighed and transferred to a $2 \mathrm{~mL}$ centrifuge tube, and methanol $(350 \mu \mathrm{L})$ was added in and mixed homogeneously; then chloroform $(700 \mu \mathrm{L})$ was added in and mixed homogeneously; then $10 \% \mathrm{NaCl}$ solution $(350 \mu \mathrm{L})$ was added and the mixture was centrifuged at $15{ }^{\circ} \mathrm{C}$ and 8,000 g for $5 \mathrm{~min}$, and then the chloroform phase was collected. Precipitates were extracted with chloroform $(350 \mu \mathrm{L})$ and the process was repeated for several times till they became colorless. Then the chloroform phases were combined and dried under $\mathrm{N}_{2}$. The extract was dissolved in diethyl ether $(50 \mu \mathrm{L})$, and then $6 \%$ methanolic $\mathrm{KOH}$ solution $(350 \mu \mathrm{L})$ was added in and incubated in the dark at $60{ }^{\circ} \mathrm{C}$ for $30 \mathrm{~min}$. Then chloroform $(700 \mu \mathrm{L})$ and $10 \% \mathrm{NaCl}$ solution $(350 \mu \mathrm{L})$ were added and mixed homogeneously, and centrifuged at $15{ }^{\circ} \mathrm{C}$ and $8,000 \mathrm{~g}$ for $5 \mathrm{~min}$. Then the chloroform phase was collected. $10 \% \mathrm{NaCl}$ solution $(700 \mu \mathrm{L})$ was added to the chloroform phase to extract $\mathrm{KOH}$ and this step was repeated several times till the water phase became neutral. The chloroform phase was blown to dryness using $\mathrm{N}_{2}$, and then stored at $-20{ }^{\circ} \mathrm{C}$ for HPLC analysis. In order to prevent photodegradation, isomerization and structure variation, the extraction of carotenoids was performed in dim light. The extraction of each sample was repeated three times.

Before HPLC analysis, the dried extract was dissolved in ethyl acetate (HPLC grade, $120 \mu \mathrm{L}$ ) and then centrifuged, and the supernatant was used for HPLC analysis. Carotenoids were analyzed on a Waters HPLC-PDAD system (Waters Corp., Milford, MA), using a $5 \mu \mathrm{m} \mathrm{C}_{30}$ reverse phase column $(250 \times 4.6 \mathrm{~mm})$ and $20 \times 4.6 \mathrm{~mm} \mathrm{C}_{30}$ guard-column and an external standard method. The column temperature was $25^{\circ} \mathrm{C}$, and the elution conditions followed the method reported by Xu et al. [26]. The results were analyzed by Waters Empower software, and carotenoids were identified by both the 
retention times and absorption spectrum curves. Lutein, zeaxanthin, $\beta$-cryptoxanthin, $\alpha$-carotene and $\beta$-carotene standards were all purchased from Sigma Chemical Co. (St. Louis, MO, USA). Neoxanthin, violaxanthin, luteoxanthin, 9-cis-violaxanthin, phytofluene, phytoene, $\zeta$-carotene and lycopene were prepared according to previous methods $[26,30]$.

\section{Conclusions}

In the present study, chromatograms of carotenoids in persimmon fruit were recorded. Nine specific carotenoids (i.e., neoxanthin, violaxanthin, 9-cis-violaxanthin, lutein, zeaxanthin, $\beta$-cryptoxanthin, $\alpha$-carotene, $\beta$-carotene and lycopene) were identified. Although the contents of the total carotenoids in the fleshes were great different from each other among different persimmon cultivars, $\beta$-cryptoxanthin and zeaxanthin were two specific carotenoids whose contents were the highest among all the persimmon flesh samples. Therefore, persimmon flesh could be utilized as one of the few abundant resources of zeaxanthin besides as a vitamin A source food. Besides the cultivar, the maturity period was also an important factor influencing the contents of carotenoids and RE values in the persimmon flesh samples.

\section{Acknowledgements}

This work was financially supported by the National Natural Science Foundation of China (30771491), China Postdoctoral Science Foundation (20100471401) and Postdoctoral Science Foundation of Jiangsu Province (0901055C). The authors are grateful to the National Persimmon Germplasm Nursery in Northwest A\&F University, Zhenjiang Agricultural Science Institute, and Persimmon Germplasm Experimental Station of Huazhong Agricultural University for kindly providing the plant materials used in this research. We also thank Institute of Agrobiology and Environmental Science, Zhejiang University for providing the carotenoid analysis.

\section{References}

1. FAO. http://faostat.fao.org/site/567/DesktopDefault.aspx?PageID=567\#ancor. Accessed on 9 November 2010.

2. Celik, A.; Ercisli, S. Persimmon cv. Hachiya (Diospyros kaki Thunb.) fruit: some physical, chemical and nutritional properties. Int. J. Food Sci. Nutr. 2007, 18, 1-8.

3. Ebert, G.; Gross, J. Carotenoid changes in the peel of ripening persimmon (Diospyros kaki) cv. Triumph. Phytochemistry 1985, 24, 29-32.

4. Gorinstein, S. Comparative content of total polyphenols and dietary fiber in tropical fruits and persimmon. J. Nutr. Biochem. 1999, 10, 367-371.

5. Yuan, B.; Xu, H.L.; Leng, S.P. Content and chemical composition of carotenoids in persimmon fruit (In Chinese). Chin. Agr. Sci. Bull. 2006, 22, 277-280.

6. Meléndez-Martínez, A.J.; Britton, G.; Vicario, I.M.; Heredia, F.J. Relationship between the colour and the chemical structure of carotenoid pigment. Food Chem. 2007, 101, 1145-1150.

7. Sánchez-Moreno, C.; Plaza, L.; de Ancos, B.; Cano, M.P. Vitamin C, provitamin A carotenoids, and other carotenoids in high-pressurized orange juice during refrigerated storage. J. Agr. Food Chem. 2003, 51, 647-653. 
8. Bartley, G.E.; Scolnik, P.A. Plant carotenoids: pigments for photoprotection, visual attraction, and human health. Plant Cell 1995, 7, 1027-1038.

9. Cooper, D.A.; Eldridge, A.L.; Peters, J.C. Dietary carotenoids and certain cancers, heart disease, and age-related macular degeneration: a review of recent research. Nutr. Rev. 1999, 57, 201-214.

10. Brossard, J.; Mackinney, G. The carotenoids of Diospyros kaki (Japanese persimmons). J. Agr. Food Chem. 1963, 11, 501-503.

11. Curl, A.L. The carotenoids of Japanese persimmons. Food Res. 1960, 25, 670-674.

12. Gross, J.; Bazak, H.; Blumenfeld, A.; Ben-Arie, R. Changes in chlorophyll and carotenoid pigments in the peel of 'Triumph' persimmon (Diospyros kaki L.) induced by pre-harvest gibberellin $\left(\mathrm{GA}_{3}\right)$ treatment. Sci. Hort. 1984, 24, 305-315.

13. Kon, M.; Shimba, R. Changes of carotenoids in Japanese persimmon (Yotsumizo) during Maturation, storage and drying process (In Japanese). Nippon Shokubin Kogyo Gakkaishi 1987, 34, 155-162.

14. Philip, T.; Chen, T.S. Quantitative analyses of major carotenoid fatty acid esters in fruits by liquid chromatography: persimmon and papaya. J. Food Sci. 1988, 53, 1720-1722.

15. Daood, H.G.; Bicas, P.; Czinkotai, B.; Hoschke, A. Chromatographic investigation of carotenoids, sugars and organic acids from Diospyros kaki fruits. Food Chem. 1992, 45, 151-155.

16. Homnava, A.; Payne, J.; Koehler, P.; Eitenmiller, R. Provatamin A (alpha-carotene, beta-carotene and beta-cryptoxanthin) and ascorbic acid content of Japanese and American persimmons. J. Food Qual. 1990, 13, 85-95.

17. Homnava, A.; Payne, J.; Koehler, P.; Eitenmiller, R. Characterization of changes during ripening of oriental persimmon. J. Food Qual. 1991, 14, 425-434.

18. Zhou, C.H.; Xu, C.J.; Li, X.; Sun, C.D.; Chen, K.S. Carotenoids in white and red-fleshed loquat fruits. J. Agr. Food Chem. 2007, 55, 7822-7830.

19. Rodrigo, M.; Marcos, J.F.; Zacarías, L. Biochemical and molecular analysis of carotenoid biosynthesis in flavedo of orange (Citrus sinensis L.) during fruit development and maturation. $J$. Agr. Food Chem. 2004, 52, 6724-6731.

20. Crisosto, C.H.; Garner, D.; Crisosto, G.M.; Sibbett, S.; Day, K.R. Late harvest and delayed cooling induce internal browning of 'Ya Li' and 'Seuri' Chinese pears. HortScience 1994, 29, 667-670.

21. Chan, H.-C.; Chang, R.C.-C.; Ip, A.K.-C.; Chiu, K.; Yuen, W.-H.; Ze, S.-Y.; So, K.-F. Neuroprotective effects of Lycium barbarum Lynn on protecting retinal ganglion cells in an ocular hypertension model of glaucoma. Exp. Neurol. 2007, 203, 269-273.

22. Inbaraj, B.S.; Lua, H.; Hung, C.F.; Wu, W.B.; Linc, C.L.; Chen, B.H. Determination of carotenoids and their esters in fruits of Lycium barbarum Linnaeus by HPLC-DAD-APCI-MS. J. Pharm. Biomed. Anal. 2008, 47, 812-818.

23. Rao, A.V.; Waseem, Z.; Agarwal, S. Lycopene content of tomatoes and tomato products and their contribution to dietary lycopene. Food Res. Int. 1998, 31, 737-741.

24. Perkins-Veazie, P.; Collins, J.K.; Davis, A.R.; Roberts, W. Carotenoid content of 50 watermelon cultivars. J. Agr. Food Chem. 2006, 54, 2593-2597.

25. Mourvaki, E.; Stefania, G.; Rossi, R.; Rufini, S. Passionflower fruit-a "new" source of lycopene? J. Med. Food 2005, 8, 104-106. 
26. Xu, C.J.; Fraser, P.D.; Wang, W.J.; Bramley, P.M. Differences in the carotenoid content of ordinary citrus and lycopene-accumulating mutants. J. Agr. Food Chem. 2006, 54, 5474-5481.

27. Fanciullino, A.-L.; Dhuique-Mayer, C.; Luro, F.; Morillon, R.; Ollitrault, P. Carotenoid biosynthetic pathway in the Citrus genus: number of copies and phylogenetic diversity of seven genes. J. Agr. Food Chem. 2007, 552, 7405-7417.

28. Niikawa, T.; Suzuki, T.; Ozeki, T.; Kato, M.; Ikoma, Y. Characteristics of carotenoid accumulation during maturation of the Japanese persimmon 'Fuyu' (In Japanese). Hortic. Res. (Japan) 2007, 6, 251-256.

29. McGuire, R.G. Reporting of objective colour measurements. HortScience 1992, 27, 1254-1255.

30. Fraser, P.D.; Pinto, M.E.S.; Holloway, D.E.; Bramley, P.M. Application of high-performance liquid chromatography with photodiode array detection to the metabolic profiling of plant isoprenoids. Plant J. 2000, 24, 551-558.

Sample Availability: Samples of the compounds are available from the authors.

(C) 2011 by the authors; licensee MDPI, Basel, Switzerland. This article is an open access article distributed under the terms and conditions of the Creative Commons Attribution license (http://creativecommons.org/licenses/by/3.0/). 